\title{
academicJournals
}

Vol. 13(40), pp. 4008-4018, 1 October, 2014

DOI: $10.5897 / A J$ B2014.14006

Article Number: 5B66B4B47962

ISSN 1684-5315

Copyright $(2014$

African Journal of Biotechnology

Author(s) retain the copyright of this artic le

http://www.academic joumals.org/A/B

\section{Effects of fermentation and extrusion on the proximate composition and organoleptic properties of sorghum- soya blend}

\author{
Anthony Okhonlaye Ojokoh* and Edith Nkechinyere Udeh \\ Department of Microbiology, Federal University of Technology, P.M.B. 704, Akure, Nigeria.
}

Received 27 June, 2014; Accepted 3 September, 2014

\begin{abstract}
The effect of extrusion and fermentation on the proximate composition and organoleptic properties of six combinations $(100: 0,90: 10,80: 20,70: 30,60: 40$ and 50:50) of sorghum - soya blend were investigated. A total number of 19 microorganisms were isolated during the fermentation of sorghum-soya extrudates; these comprise of twelve (12) bacteria, four (4) yeast and three (3) moulds. They include Flavobacterium rigense, Micrococcus icristinae, Enterobacter cloacae, Enterobacter spp., Corynebacterium cystitidis, C. pilosun, Staphylococcus albus, Brevibacterium spp., Bacillus subtilis, B. cereus, B. brevis, B. megaterium, Candida famata, Saccharomyces cerevisiae, Geotrichum candidium, C. utilis, Aspergillus niger, A. fumigatus and Rhizopus stolonifer. The $\mathrm{pH}$ and the total titratable acidity (TTA) significantly varied during fermentation. The proximate composition of the raw flour blend, unfermented and fermented extrudates was assessed. The crude protein and moisture contents increased in the extruded and fermented samples whereas; extrusion and fermentation reduced the ash and carbohydrate contents. Crude fibre and fat contents varied among all the samples. The sensory evaluation of the unfermented extrudates indicated a good preference for the product in term of colour, texture, aroma and overall acceptability.
\end{abstract}

Key words: Fermentation, extrusion, sorghum-soya blend, proximate, orgnoleptic.

\section{INTRODUCTION}

In Nigeria and many other developing countries of the tropics, protein deficiency in diets is common and is usually found in association with deficiency in calories. Since the diet of an average Nigerian consists of foods that are mostly carbohydrate based, there is a need for strategic use of inexpensive high protein resources that complement the amino acid profile of staple diet in order to enhance their nutritive value. According to Edema et al. (2005) newer protein sources are being explored as protein complements of which oil seeds occupy a prominent place. New food processing technologies can provide a means of improving the nutritional quality of

${ }^{*}$ Corresponding author. E-mail: tonyojokoh@yahoo.com.

Author(s) agree that this article remain permanently open access under the terms of the Creative Commons Attribution License 4.0 International License 
Table 1. Level combinations of sorghum and soya bean blends.

\begin{tabular}{cc}
\hline Sorghum $\mathbf{( g )}$ & Soya flour(g) \\
\hline 100 & 0 \\
90 & 10 \\
80 & 20 \\
70 & 30 \\
60 & 40 \\
50 & 50 \\
\hline
\end{tabular}

food plants, which are the most important dietary sources for meeting the nutritional needs of majority of the population in Nigeria because they are readily available, low in cost and acceptable. Traditionally, cereals and legumes have been processed in homes as part of preparing food for families and one of the oldest ways of processing food at home is by fermentation. The practice of blending locally grown crops in Nigeria partly for aesthetic purposes and nutrient supplementation has been an age long tradition. Fermentation as described by Ojokoh et al. (2003) is a complex chemical transformation of organic substances brought about by the catalytic action of enzymes (either native or elaborated by the microorganisms) fermenting the raw materials.

Extrusion cooking is a relatively recent form of food processing forcing food material through dies with holes of various shapes. Material is continuously metered into an inlet hopper and then transported forward by a rotating screw. As the material approaches the die, there is an increase in pressure and temperature. It involves heat, pressure and shear (Mills et al., 1993). Blended foods prepared by mixing cereal flour (usually maize flour) with soy flour to get a high protein food with good balance of amino acids are widely used in food aid programmes. Blended foods are usually pre-cooked by extrusion so that less cooking time is required and to improve shelflife. Extrusion cooking technique is used in processing a wide range of products for both human and animal consumption (Guy, 2001). Extrusion cooking was adopted for use in nutrition intervention projects mostly for malnourished individuals in many less developed continents like Asia, Latin America and Africa (Osundahunsi, 2006). Functional ingredients such as soy and botanicals that are relatively unpalatable alone can be incorporated into new food items by extrusion. Traditional foods can be further enhanced by addition of dietary fibre or other ingredients during extrusion. According to Iwe (1998), developing countries have been in search of technologies to produce low cost nutrition food and alternative procedures to process soy based food in less developed countries (LDCs). Extrusion has therefore been found to be versatile, cost effective, and acceptable in the LDCs. Extrusion cooking of corn and soya bean and their various blends has been reported in most available literature; information is lacking on the extrusion of sorghum blended with soya bean flour as combined with fermentation. The objective of the present research was to investigate the combined influence of extrusion and fermentation on the proximate composition and organoleptic properties of sorghum - soya blend

\section{MATERIALS AND METHODS}

The sorghum (Sorghum bicolour) grains used for the research study was purchased from Oba's market Akure, while soya beans seeds (Glycogen max) Variety TGX 1448-2E was obtained from International Institute for Tropical Agriculture (IITA), Ibadan, Nigeria.

Production and fermentation of sorghum-soya blends and extrudate

The dried sorghum grains were sorted by hand to remove leaves, stones and other foreign materials. The cleaned grains were then fed into an attrition mill (ASIRO All Double Grinding Machine) and ground coarsely. The coarsely grinded sorghum was winnowed to remove the bran, milled to fine flour in the attrition mill and then sieved to fineness.

The cleaned soya bean seeds were first coarsely milled, winnowed to separate the coat and finished up in attrition mill. The fine flour was then sieved through a mesh. The fine flour was defatted with n-hexane in cold extraction from $20.57 \%$ fat content to $15.17 \%$. The recovered flour was air dried and the clumps broken to fines. The flour samples from sorghum and soya bean were mixed at six level combinations as shown in Table 1. The flour samples were stored in clean sterile transparent polythene bags, tightened at the tips and kept in another bag until used.

The flour blends were hydrated and preconditioned by adding appropriate amount of water and manually mixed in a wide bowl to ensure even moisture distribution and processed in a laboratory single screw extruder (Hobart Corporation Germany) at screw speed of $80 \mathrm{rpm}$ and through a die nozzle diameter of $5 \mathrm{~mm}$ at $110^{\circ} \mathrm{C}$. The extrudates obtained were allowed to cool and dry before fermentation.

A $100 \mathrm{~g}$ portion of each extrudate was weighed and $50 \mathrm{ml}$ of water was added. The samples were allowed to ferment at $30 \pm 2^{\circ} \mathrm{C}$ for $96 \mathrm{~h}$. The fermented samples were oven dried at $500^{\circ} \mathrm{C}$ for $24 \mathrm{~h}$.

\section{Microbiological analyses of the extrudates}

Microbial population of the total bacterial and fungi were determined using nutrient agar (NA) and Potato dextrose agar (PDA) respectively; organisms were enumerated by using appropriate serial dilution and pour plate techniques. The bacterial cultures were incubated at in inverted position at $37 \pm 2^{\circ} \mathrm{C}$ for $24 \mathrm{~h}$ while the fungi plates were incubated in an inverted position at $25 \pm 2^{\circ} \mathrm{C}$ for 72 $\mathrm{h}$ (3days). The organisms were characterized based on biochemical and morphological observations and tests (Cowan and Steel, 1990).

\section{Physiochemical changes}

\section{Determination of $\mathrm{pH}$}

The $\mathrm{pH}$ of all the fermenting samples (extrudates) was determined 
Table 2. Seven-point hedonic scale.

\begin{tabular}{cl}
\hline Point score & Point linguistic value \\
\hline 7 & Like very much \\
6 & Moderately \\
5 & Like Slightly \\
4 & Neither like nor dislike \\
3 & Dislike slightly \\
2 & Dislike moderately \\
1 & Dislike very much \\
\hline
\end{tabular}

at twenty-four (24) hour intervals using pocket size digital $\mathrm{pH}$ meter (PHC.P (R) Hanna instrument).

\section{Determination of total titratable acidity (TTA)}

The total titratable acidity of the fermenting extrudates was determined every twenty-four hour as described by AOAC (1990). A $2 \mathrm{~g}$ of macerated sample was weighed, $50 \mathrm{ml}$ of distilled water was added and then filtered. A $10 \mathrm{ml}$ of the filtrate was measured and few drops of Phenolphthalein indicator were added. This was titrated with $0.1 \mathrm{~m}$ sodium hydroxide $(\mathrm{NaOH})$ solution and the titre values in millilitre were read from the burette. The acidity was calculated as follows:

Total titratable acidity was expressed as percent (\%) lactic acid, where $1 \mathrm{ml}$ of $0.1 \mathrm{~m} \mathrm{NaOH}$ is equivalent to 0.09008 lactic acid (Kirk and Sawyer, 1991).

TTA $=$ Titre Value $\times$ Volume of Sample $\times 9 \mathrm{mg} / 100 \mathrm{~g}$

\section{Proximate analysis}

Moisture content was determined by direct oven drying method; the loss in weight after oven-drying was expressed as \% moisture content (AOAC, 1990). Crude protein was estimated from the total nitrogen (TN) determined by the micro-Kjeldahl method by multiplying the TN by a factor of 6.25 . Crude fat was determined by using the soxhlet extraction method using petroleum ether as the solvent (AOAC, 1990). Ash was measured gravimetrically after ashing at $550^{\circ} \mathrm{C}$ to constant weight. Carbohydrate was determined by difference.

\section{Sensory evaluation}

The design and analysis for evaluation of sensory acceptability as detailed by Ihekoronye and Ngoddy (1985) was employed for the consumer acceptability test. A panel of the judges (untrained but familiar with extruded product such as pasta, noodles, breakfast cereal quality characteristic) was set up. The panellists were asked to express their feeling about the samples based on colour, aroma, texture and general acceptability by scoring them on a seven- point hedonic scale (Table 2).

\section{Statistical analysis}

The data obtained were subjected to one way analysis of variance (ANOVA) followed by Turkey's test multiple comparisons using
SPSS 17.0 version computer software package. The values were considered significant at $p \leq 0.05$.

\section{RESULTS \\ Microbial growth during fermentation of sorghum- soya extrudates}

\section{Microorganisms isolated during the fermentation of sorghum-soya extrudates}

A total number of 19 microorganisms were isolated during the fermentation of sorghum-soya extrudates (Figure 1). These comprise of twelve (12) bacteria, four (4) yeast and three (3) moulds. They include Flavobacterium rigense, Micrococcus icristinae, Enterobacter cloacae, Enterobacter spp., Corynebacterium cystitidis, C. pilosun, Staphylococcus albus, Brevibacterium spp., Bacillus subtilis, $B$. cereus, $B$. brevis, $B$. megaterium, Candida famata, Saccharomyces cerevisiae, Geotrichum candidium, C. utilis, Aspergillus niger, A. fumigatus and Rhizopus stolonifer.

\section{Changes in $\mathrm{pH}$ during the fermentation of sorghum- soya extrudates}

The $\mathrm{pH}$ variations during the fermentation of sorghumsoya extrudates are shown in Figure 2. Extrudate A gradually decreased from $6.30 \pm 0.1$ to $3.34 \pm 0.11$, extrudate $B$ decreased from $6.43 \pm 0.15$ to $3.33 \pm 0.06$. In extrudate $C$, the initial $\mathrm{pH}$ was $6.3 \pm 0.00$. This decreased to $5.83 \pm 0.01$ at $72 \mathrm{~h}$ and later increased to $6.00 \pm 0.00$. Extrudate $\mathrm{D}$ decreased from $6.33 \pm 0.06$ to $4.10 \pm 0.10$ at $72 \mathrm{~h}$ and increased to $5.17 \pm 0.12$ at $96 \mathrm{~h}$. Extrudate $\mathrm{E}$ decreased from $6.47 \pm 0.12$ to $4.23 \pm 0.06$ at $72 \mathrm{~h}$ and increased to $6.17 \pm 0.06$ at $96 \mathrm{~h}$. Extrudate $\mathrm{F}$ decreased from $6.40 \pm 0.10$ to $5.03 \pm 0.06$ at $24 \mathrm{~h}$. It increased to $5.93 \pm 0.56$ at $48 \mathrm{~h}$ through $6.83 \pm 0.23$ at $96 \mathrm{~h}$ of fermentation.

\section{Changes in total titratable acidity (TTA) during the fermentation of sorghum-soya extrudates}

Variations in titratable acidity (TTA) during fermentation of sorghum-soya extrudates are represented in Figure 3. Extrudate A had TTA of $0.0843 \pm 0.0006$; this increased to $0.3213 \pm 0.002$ at $72 \mathrm{~h}$ and decreased slightly to $0.3213 \pm 0.002$. Extrudate $B$ increased from $0.2077 \pm$ 0.002 to $0.2230 \pm 0.001$ at $24 \mathrm{~h}$, it decreased slightly and increased to $0.3320 \pm 0.002$ and finally reduced to 0.3120 \pm 0.002 at $96 \mathrm{~h}$. Extrudate $\mathrm{C}$ increased from $0.0523 \pm 0.002$ to $0.1560 \pm 0.003$ at $72 \mathrm{~h}$ and decreased to $0.1483 \pm 0.001$ at $96 \mathrm{~h}$. Extrudate $\mathrm{D}$ increased from $0.1123 \pm 0.002$ to $0.3733 \pm 0.12$ at $72 \mathrm{~h}$ and decreased to $0.3607 \pm 0.001$ 


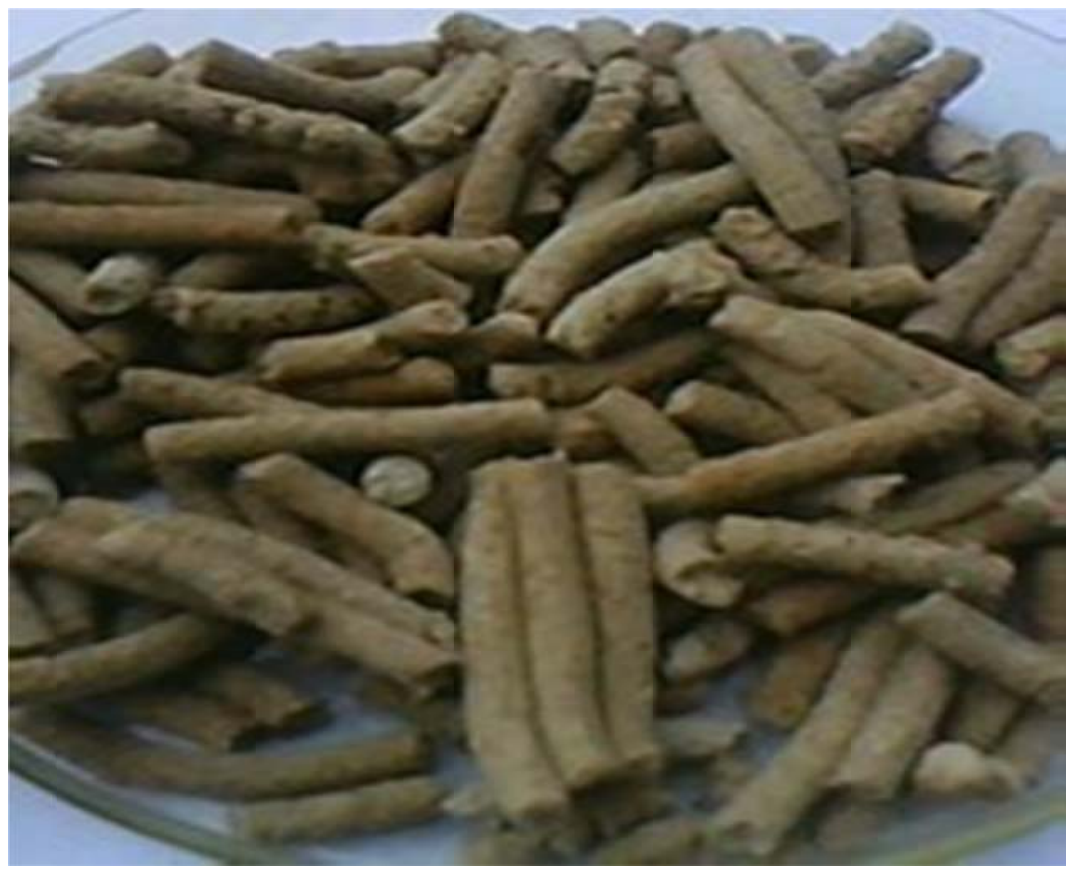

Figure 1. Sorghum-soya extrudate.

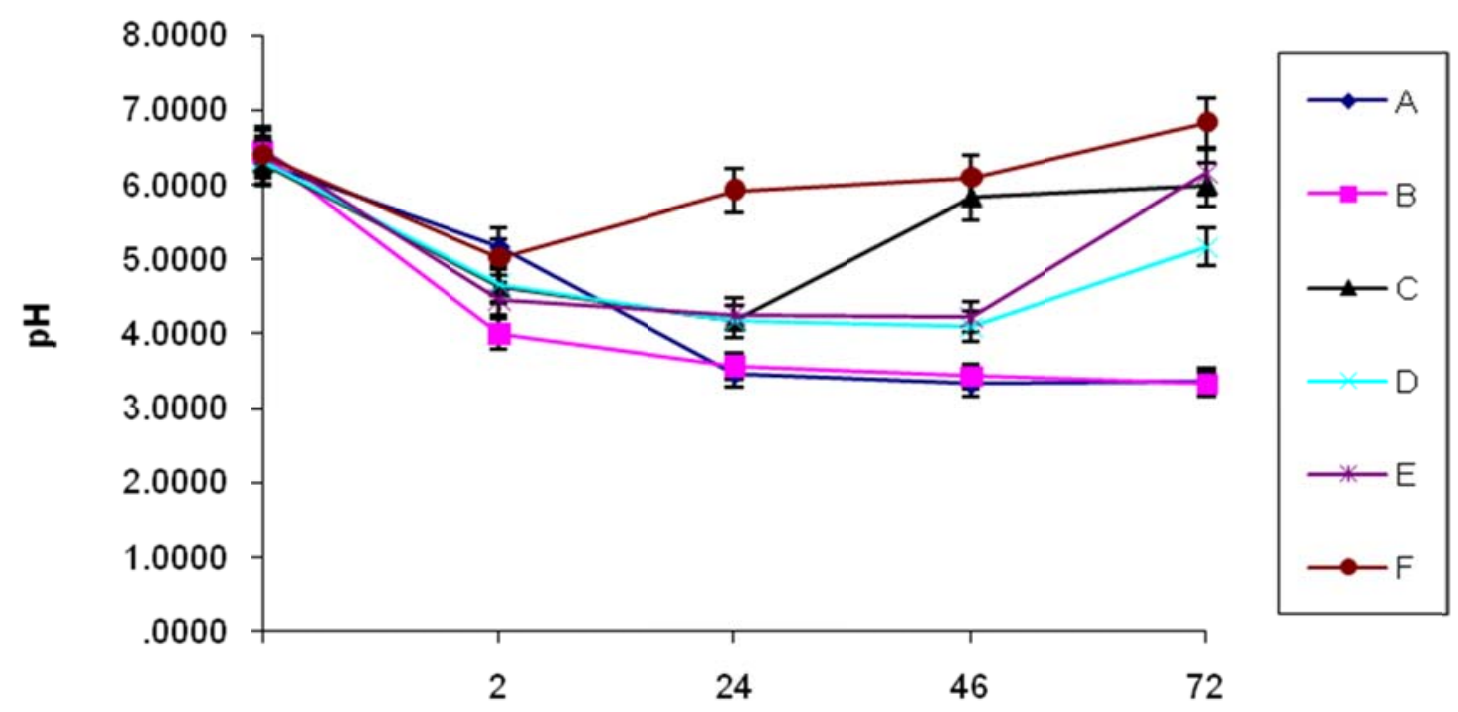

Time (h)

Figure 2. $\mathrm{pH}$ variations during fermentation of sorghum-soya extrudates. $A=100 \mathrm{~g}$ sorghum flour sample; $B$ $=90$ and $10 \mathrm{~g}$ sorghum-soya blend sample; $\mathrm{C}=80$ and $20 \mathrm{~g}$ sorghum-soya blend sample; $\mathrm{D}=70$ and $30 \mathrm{~g}$ sorghum-soya blend sample; $\mathrm{E}=60$ and $40 \mathrm{~g}$ sorghum-soya blend sample; $\mathrm{F}=50$ and $50 \mathrm{~g}$ sorghum-soya blend sample.

at $96 \mathrm{~h}$. Extrudate $\mathrm{E}$ increased from $0.0637 \pm 0.001$ to $0.2107 \pm 0.11$ at $72 \mathrm{~h}$ and decreased to $0.1757 \pm 0.001$ at
96 h. Extrudate $F$ increased from $0.0767 \pm 0.002$ to $0.3477 \pm 0.002$ at $72 \mathrm{~h}$ and decreased to $0.3403 \pm 0.001$ 


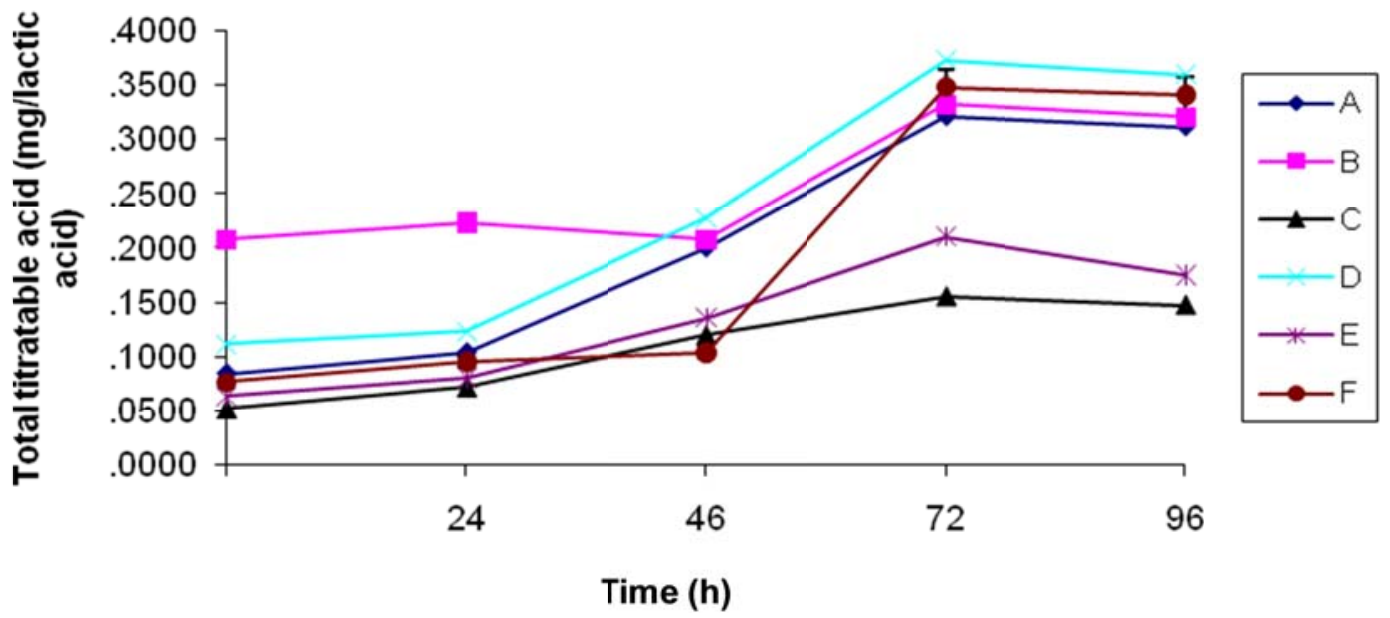

Figure 3. Total titratable acidity (tta) variation during fermentation of sorghum-soya extrudates. $A=100$ $\mathrm{g}$ sorghum flour sample; $\mathrm{B}=90$ and $10 \mathrm{~g}$ sorghum-soya blend sample; $\mathrm{C}=80$ and $20 \mathrm{~g}$ sorghum-soya blend sample; $\mathrm{D}=70$ and $30 \mathrm{~g}$ sorghum-soya blend sample; $\mathrm{E}=60$ and $40 \mathrm{~g}$ sorghum-soya blend sample; $\mathrm{F}=50$ and $50 \mathrm{~g}$ sorghum-soya blend sample.

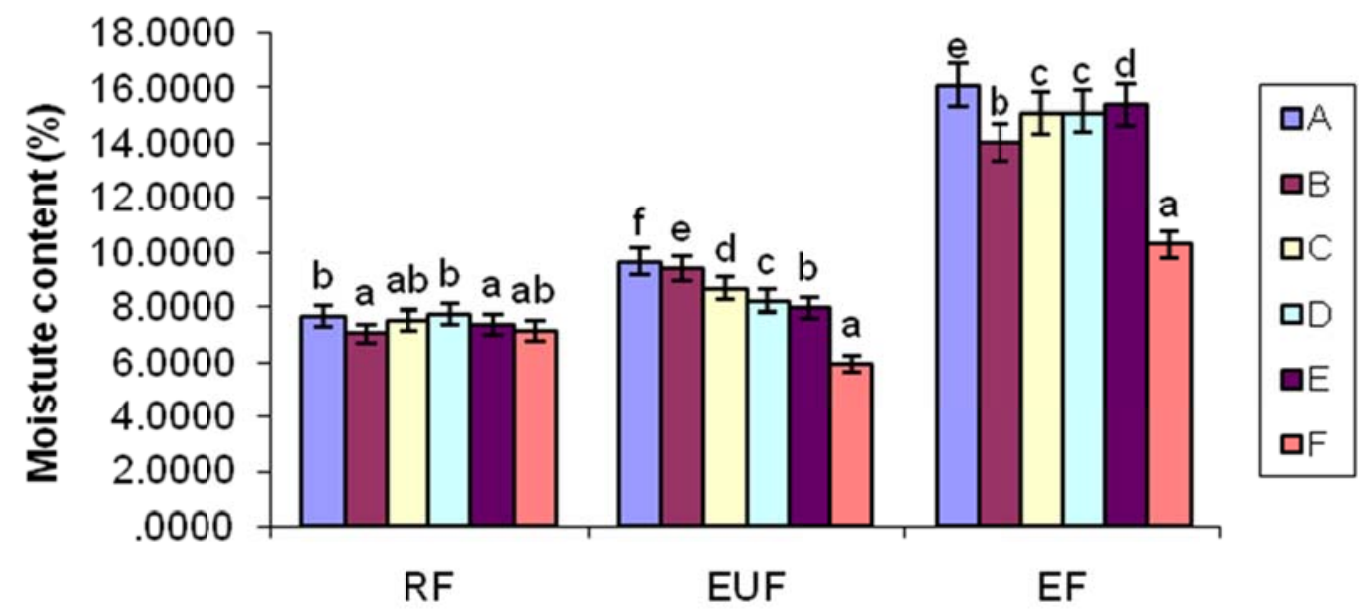

Figure 4. Moisture content of sorghum-soya blends and extrudates. RF = raw flour; EUF = extruded unfermented; $E F=$ extruded fermented; $A=100 \mathrm{~g}$ sorghum flour sample; $B=90$ and $10 \mathrm{~g}$ sorghumsoya blend sample; $\mathrm{C}=80$ and $20 \mathrm{~g}$ sorghum-soya blend sample; $\mathrm{D}=70$ and $30 \mathrm{~g}$ sorghum-soya blend sample; $\mathrm{E}=60$ and $40 \mathrm{~g}$ sorghum-soya blend sample; $\mathrm{F}=50$ and $50 \mathrm{~g}$ sorghum-soya blend sample.

at $96 \mathrm{~h}$ of fermentation.

\section{Changes in proximate composition of sorghum-soya blends and extrudates}

\section{The moisture composition of sorghum-soya blends and extrudates}

The moisture content of sorghum-soya blends and extru- dates are represented in Figure 4. Raw flour blends had the lowest moisture content with raw flour (RF) A-F ranging from 7.69 to $7.14 \pm 0.27$. There were no significant difference $(P \leq 0.05)$ in the raw flour $A$ and $D$, between $B$ and $E$ and between $C$ and $F$. The moisture content of extruded unfermented (EUF) samples ranged between $5.89 \pm 0.01$ and $9.65 \pm 0.01$. There was significant difference $(P \leq 0.05)$ among all the extruded unfermented samples (EUF). Extruded fermented (EF) samples exhibited moisture content of $10.29 \pm 0.01$ for 


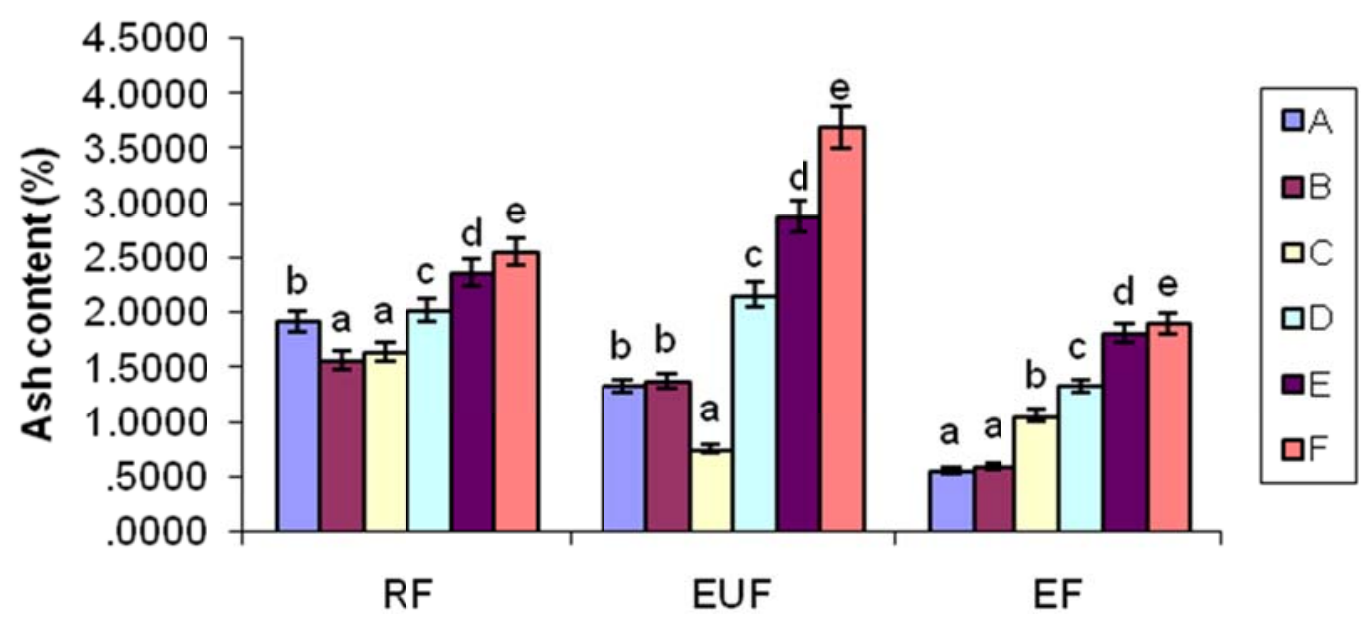

Figure 5. ASH content of sorghum-soya blends and extrudates. RF = Raw flour; EUF = extruded unfermented; $E F=$ extruded fermented; $A=A=100 \mathrm{~g}$ sorghum flour sample; $B=90$ and $10 \mathrm{~g}$ sorghum-soya blend sample; $\mathrm{C}=80$ and $20 \mathrm{~g}$ sorghum-soya blend sample; $\mathrm{D}=70$ and $30 \mathrm{~g}$ sorghumsoya blend sample; $\mathrm{E}=60$ and $40 \mathrm{~g}$ sorghum-soya blend sample; $\mathrm{F}=50$ and $50 \mathrm{~g}$ sorghum-soya blend sample.

extrudate $\mathrm{F}$ and $16.11 \pm 0.02$ for extrudate $\mathrm{A}$. There was no significant difference $(P \leq 0.05)$ between extrudates $C$ and $D$, while the moisture content was significantly $(P \geq 0.05)$ recorded among extrudates $A, B, E$ and $F$.

\section{The ash composition of sorghum-soya blends and extrudates}

The changes in the ash content of the sorghum-soya blends and extrudates are represented in Figure 5. Extruded fermented (EF) samples recorded the lowest ash content between $0.5467 \pm 0.04$ for extrudate $A$ and $1.90 \pm 0.03$ for extrudate $F$. There was no significant difference $(P \geq 0.05)$ between extrudates $A$ and $B$, but all other extruded fermented samples were significantly different $(P \leq 0.05)$ among samples $C, D, E$ and $F$. There was no significant difference $(P \geq 0.05)$ between $A$ and $B$ for unfermented extruded (EUF) samples, while $C, D, E$ and $F$ recorded significant $(P \leq 0.05)$ difference. For the raw flour blends (RF), $\mathrm{F}$ had the highest ash composition of $2.02 \pm 0.37, B$ and $C$ had no significant $(P \geq 0.05)$ difference. Samples $A, D, E$ and $F$ were significantly different $(P \leq 0.05)$.

\section{The crude fat composition of sorghum-soya blends and extrudates}

The crude fat content of the sorghum-soya blends and extrudates are shown in Figure 6. There were significant $(p \leq 0.05)$ changes in the fat content of the raw flour blends $A$ to $F$ with raw flour blend $A$ having $2.89 \pm 0.04$ and $F, 17.35 \pm 0.01$. The extruded unfermented (EUF) had no significant $(P \geq 0.05)$ values among extrudates $A$, $C$ and $E$, with $11.80 \pm 0.01$ for extrudate $A$ and $15.33 \pm$ 0.85 for extrudate $E$. Extruded fermented (EF) samples were significant $(p \leq 0.05)$ for extrudates $B, C, E$ and $F$ with lowest significance $8.30 \pm 0.01$ ) for extrudate $B$ and highest (12.78 \pm 0.02 ) for extrudate $F$, while there was no significant difference $(p \geq 0.05)$ between $A$ and $D$.

\section{The crude fibre composition of sorghum-soya blends and extrudates}

The crude fibre content of the sorghum-soya blends and extrudates are shown in Figure 7. There was no significance $(P \geq 0.05)$ for sample $A(1.70 \pm 0.04)$ and $B$ $(1.78 \pm 0.02)$ for raw flour blends (RF). There exists significance among $\mathrm{C}, \mathrm{D}, \mathrm{E}$ and $\mathrm{F}$ with lowest significance for $C(1.34 \pm 0.03)$ and highest $(2.87 \pm 0.04)$ for sample $F$. There was significant difference $(P \leq 0.05)$ for extruded unfermented (EUF) with lowest $(1.35 \pm 0.01)$ for $B$ and highest $(4.00 \pm 0.02)$ for sample F. Extruded fermented $(E F)$ recorded no significant difference $(P \geq 0.05)$ between sample $C$ and $D$ and significant difference $(P \leq 0.05)$ among $A, B, E$ and $F$ with lowest significant for $A(0.79 \pm 0.02)$ and highest for $E(3.71 \pm 0.01)$.

The crude protein composition of sorghum-soya blends and extrudates

Significant $(P \leq 0.05)$ values were obtained among samples $A$ to $F$ for raw flour blends (RF) with lowest (9.88 


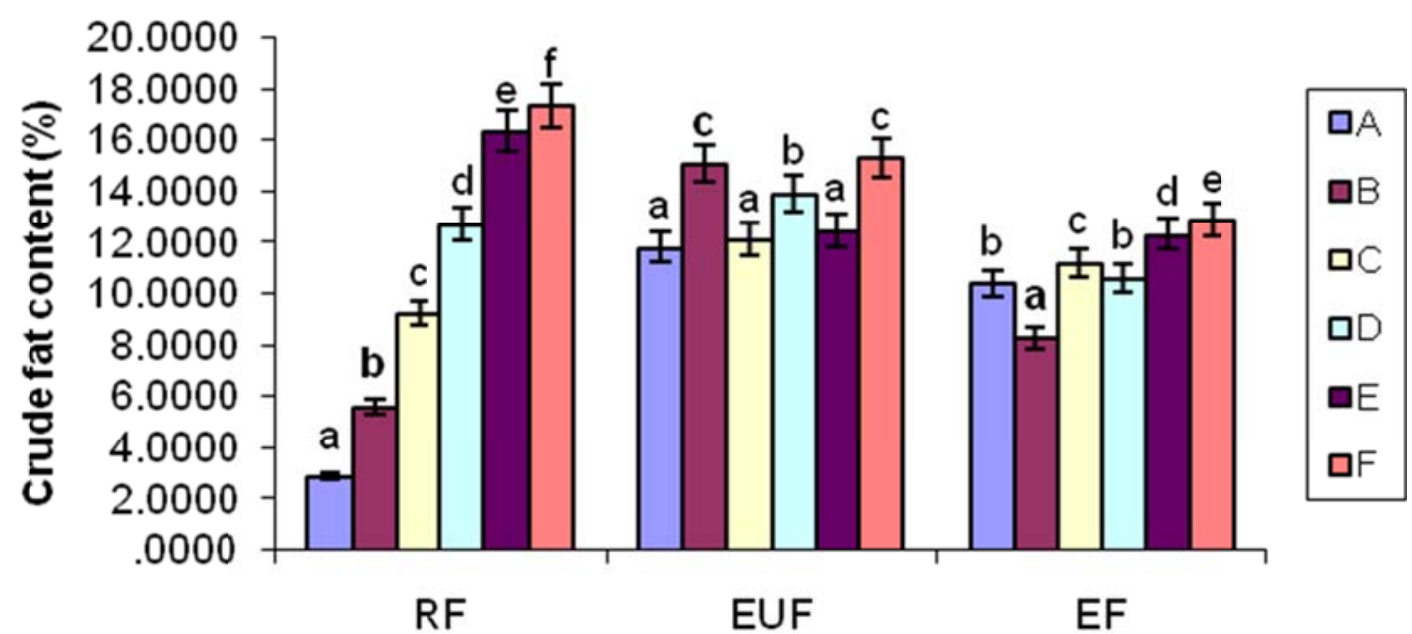

Figure 6: crude fat content of sorghum-soya blends and extrudates. RF = Raw flour; EUF = extruded unfermented; $E F=$ extruded fermented. $A=100 \mathrm{~g}$ sorghum flour sample; $B=90$ and $10 \mathrm{~g}$ sorghum-soya blend sample; $\mathrm{C}=80$ and $20 \mathrm{~g}$ sorghum-soya blend sample; $\mathrm{D}=70$ and 30 $\mathrm{g}$ sorghum-soya blend sample; $\mathrm{E}=60$ and $40 \mathrm{~g}$ sorghum-soya blend sample; $\mathrm{F}=50$ and $50 \mathrm{~g}$ sorghum-soya blend sample.

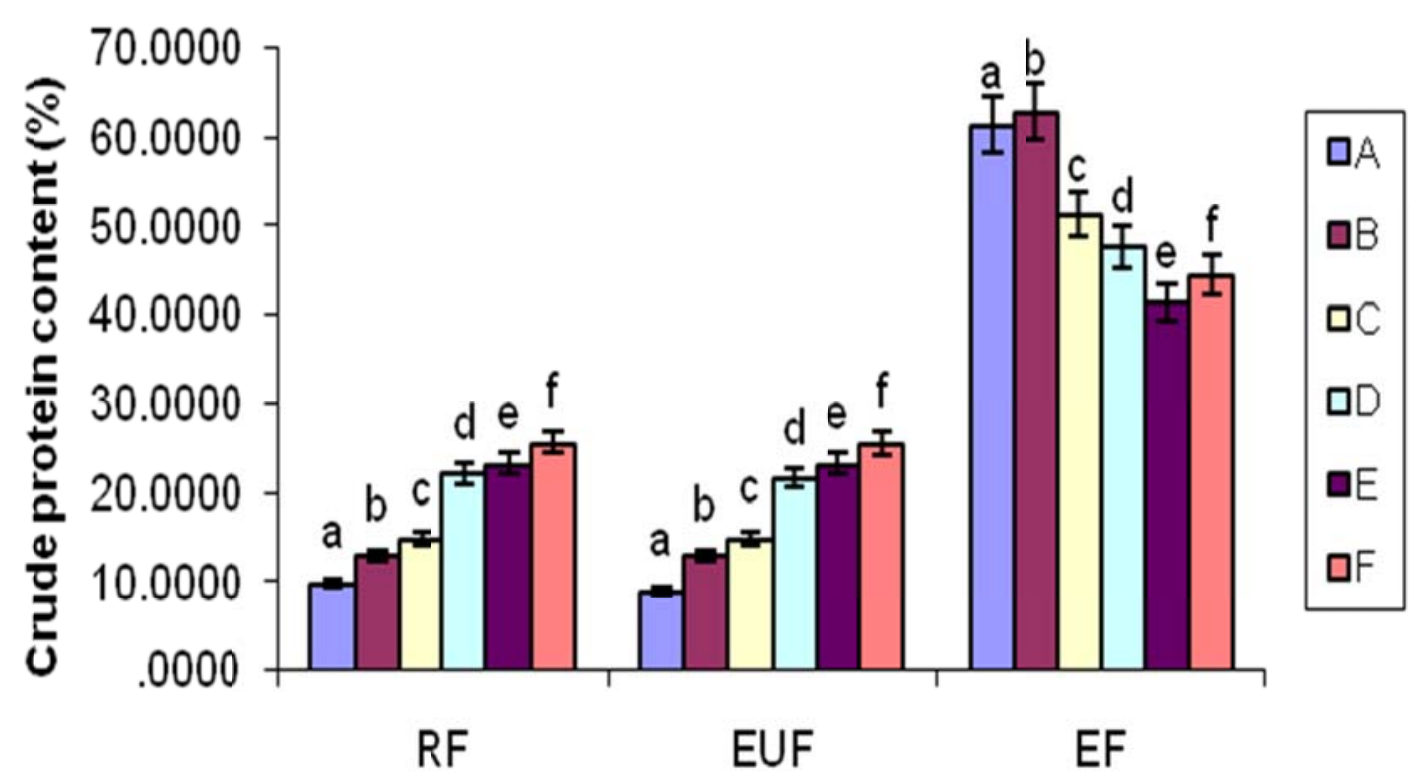

Figure 8. Crude protein content of sorghum-soya blends and extrudates. RF = Raw flour; EUF = extruded unfermented; $E F=$ extruded fermented; $A=100 \mathrm{~g}$ sorghum flour sample; $B=90$ and $10 \mathrm{~g}$ sorghum-soya blend sample; $C=80$ and $20 \mathrm{~g}$ sorghum-soya blend sample; $\mathrm{D}=70$ and $30 \mathrm{~g}$ sorghum-soya blend sample; $\mathrm{E}=60$ and $40 \mathrm{~g}$ sorghum-soya blend sample; $\mathrm{F}=50$ and $50 \mathrm{~g}$ sorghum-soya blend sample.

$\pm 0.01)$ for $A$ and highest $(25.63 \pm 0.02)$ in $F$. Extruded unfermented (EUF) samples recorded significant $(P \leq 0.05)$ changes. Changes exist among $A-F(9.01 \pm 0.02$ for $A$ and $25.10 \pm 0.01$ for $F)$. Extruded fermented (EF) exhibited significant $(P \leq 0.05)$ values for samples $A-F$ (Figure 8$)$.

\section{The carbohydrate composition of sorghum-soya blends and extrudates}

The raw flour blends $(R F)$ exhibited significant $(P \leq 0.05)$ values among samples A-F with lowest $(44.45 \pm 0.26)$ for 


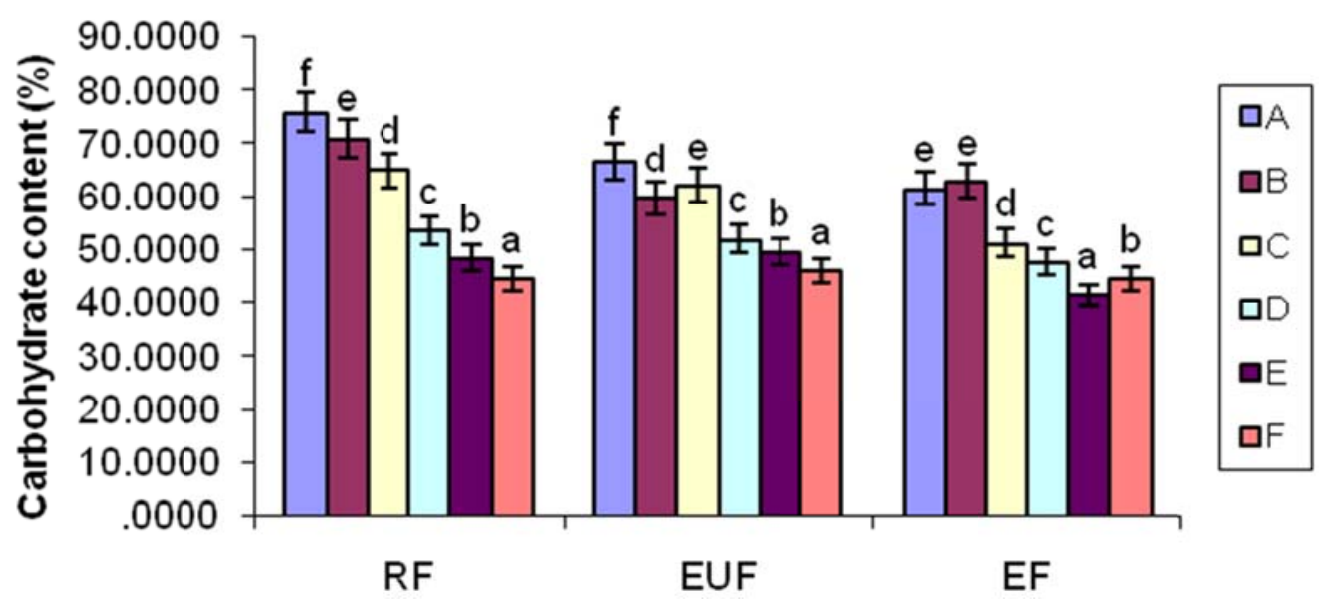

Figure 9. Carbohydrate content of sorghum-soya blends and extrudates. RF = Raw flour; EUF = extruded unfermented; $E F=$ extruded fermented; $A=100 \mathrm{~g}$ sorghum flour sample; $B=90$ and $10 \mathrm{~g}$ sorghum-soya blend sample; $\mathrm{C}=80$ and $20 \mathrm{~g}$ sorghum-soya blend sample; $\mathrm{D}=70$ and $30 \mathrm{~g}$ sorghum-soya blend sample; $\mathrm{E}=60$ and $40 \mathrm{~g}$ sorghum-soya blend sample; $\mathrm{F}=50$ and $50 \mathrm{~g}$ sorghum-soya blend sample.

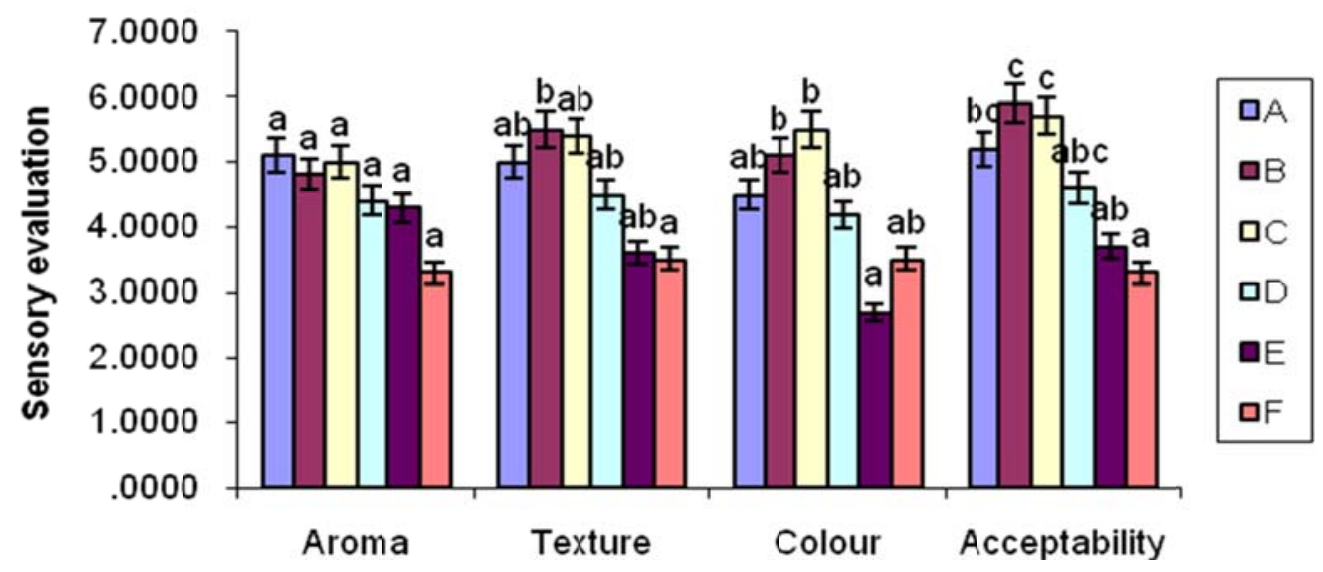

Figure 10. Sensory evaluation of sorghum-soya extrudates. $A=100 \mathrm{~g}$ sorghum flour sample; $B=$ 90 and $10 \mathrm{~g}$ sorghum-soya blend sample; $\mathrm{C}=80$ and $20 \mathrm{~g}$ sorghum-soya blend sample; $\mathrm{D}=70$ and $30 \mathrm{~g}$ sorghum-soya blend sample; $\mathrm{E}=60$ and $40 \mathrm{~g}$ sorghum-soya blend sample; $\mathrm{F}=50$ and $50 \mathrm{~g}$ sorghum-soya blend sample.

$F$ and highest $(75.92 \pm 0.31)$ for $A$. The values are significantly different $(P \leq 0.05)$ for extruded unfermented (EUF) among A-F, lowest (46.03 \pm 0.84$)$ value for sample $F$ and highest $(66.58 \pm 0.12)$ for $A$. The extruded fermented (EF) samples recorded no significant $(p \geq 0.05)$ difference between sample $A$ and $B$, while there were significant values $(P \leq 0.05)$ among $C, D, E$ and $F$ with lowest (44.46 \pm 0.04$)$ (Figure 9).

\section{Sensory evaluation of sorghum-soya extrudates}

The result obtained in the sensory evaluation indicated that there was no significant $(p \geq 0.05)$ difference in aroma for sorghum-soya extrudate unfermented (EUF). Texture was not significantly different among samples $A, C, D$ and $E$. There was significant lower $(3.5 \pm 2.17)$ difference between $F$ and higher $(5.00 \pm 1.08)$ for sample $B$. For colour there was no significant difference among $A, D$, and $F$, no significant value between $B$ and $C$ and significant difference was recorded in sample $E$. Acceptability was not significant between samples $B$ and C. Among $A, D$ and $E$, difference was noted, but not significant. Also difference was recorded among $D, E$, and $F$ but not significant. Among $A, B, C$ and $E$ values were significantly different (lowest $3.30 \pm 1.70$ in $F$ and highest $5.90 \pm \mathrm{inB}$ ). Sample B had highest acceptability of the six (6) samples. This result is represented in Figure 10. 


\section{DISCUSSION}

The initial low bacteria count of the extrudates is probably due to the heat treatment given to the samples before fermentation. The increase in bacteria population with time between 0 to $48 \mathrm{~h}$ could be attributed to various microorganisms adapting to the fermentation environment and the decrease at later hour (72 to 96 ) may be due to reduction in $\mathrm{pH}$ which would had inhibited some microbial growth in the fermenting media. As fermentation progressed, some extrudates exhibited undulating $\mathrm{pH}$ values (though this has not been reported) which could be related to dispersion of different molecules during extrusion cooking prior to fermentation. The lowering of $\mathrm{pH}$ could probably be due to the more carbohydrate composition in sorghum-soya blend extrudates which could have degraded to organic acids in extrudates $A$ and $B$, while the more availability of protein constituents in extrudates $\mathrm{E}$ and $\mathrm{F}$ might have contributed to the increase in corresponding increase in $\mathrm{pH}$. However, the result suggest that the fermentation research is lactic type since Ezeama and Ihezie (2006) had once reported that cereal fermentation is lactic type where $\mathrm{pH}$ of fermenting mass decrease with increase in total titratable acidity (TTA) and vice versa. Omafuvbe et al. (2007) had earlier reported that increase in $\mathrm{pH}$ is a common feature in the fermentation of vegetable proteins. The behavioural changes in total titratable acidity (TTA) correspond with changes in $\mathrm{pH}$ but the undulating pattern of the total titratable acidity (TTA) in the fermenting mass may be as a result of variations in the composition of soya bean supplementation levels.

The microbial flora of the fermenting media were heterogeneous comprising of 12 genera of bacteria ( $F$. rigense, M. icristinae, Enterobacter spp., E. cloacae, $C$. cystitidis, C. pilosun, S. albus, Brevibacterium spp., B. subtilis, $B$. cereus, $B$. brevis and $B$. megaterium), four yeast (C. famata, S. cerevisiae, $G$. candidium and $C$. utilis) and three moulds ( $A$. niger, $A$. fumigatus and $R$. Stolonifer). This is similar to the findings of Efiuvwevwere and Akoma (1997) that soya bean supplemented products had greater microbial diversity and higher microbial population. Enterobacter species were identified at 0 and $24 \mathrm{~h}$ of fermentation in extrudate $\mathrm{B}$ and $\mathrm{C}$, however as fermentation progressed, these less desirable bacteria disappeared. The involvement of Enterobacter species may be attributed to handling and normal contaminants. At $48 \mathrm{~h}$, Bacillus species constituted the major bacteria in extrudate $\mathrm{B}$ to $\mathrm{F}$, while $R$. stolonifer was the dominant fungi in extrudates $E$ and $F$. This could be due to the microbial flora associated with soya bean grain as these have higher percentage of soya bean supplementation. Since the major components of these extrudates are protein, fat and carbohydrate, the organisms responsible for the fermentation must have the ability of utilizing these three components and most of the isolated organisms from the fermenting extrudates have such characteristics which include Bacillus, Micrococcus and Staphylococcus species. As noted earlier, Bacillus species were the dominant bacteria in all extrudates at 48 h except in extrudate A with no soya bean supplement. Enujiugha (2009) confirmed that Bacillus species are known to have proteolytic ability and are also able to break down oil. Although other bacteria were isolated, they appear not to have great influence in the fermentation process as Bacillus species constitute $99 \%$ of the total bacteria at $48 \mathrm{~h}$. This could be due to the fact that Bacillus cells exhibit very high protease activities as compared with all other bacteria isolated.

Moisture content is one of the most important and commonly measured properties of different food products. It is measured for various reasons including legal and label requirements, economic importance, food quality, better processing operations and storagability. The nonsignificant difference $(p \geq 0.05)$ of extrudate $A$ and $D, B$ and $E$ and significant difference $(p \leq 0.05)$ of $C$ and $F$ of raw flour blends (RF) indicate to a great extent the storagability and stable shelf life of the raw flour before the commencement of extrusion and fermentation processes. The increase in moisture content after extrusion and fermentation is due to the hydration of the flour prior to extrusion and addition of water before fermentation. The increased significant difference $(p \leq 0.05)$ among extruded unfermented $A$ to $F$ indicate little reconstitution in just a little water prior to consumption thereby causing reduction in cooking time and fuel consumption.

The ash content is an inorganic residue remaining after the removal of the water and organic matter which provides a measure of total amount of minerals in the food component. Figure 5 shows the significantly $(p \leq 0.05)$ lower ash content values recorded in the extruded fermented (EF) samples as compared with that of raw flour blends (RF) and extruded unfermented (EUF) which could be as a result of the retting of the extrudates there by encouraging the leaching of water soluble mineral content of the extrudates during the fermentation process and this loss of minerals could have served as the mineral source for the fermenting microorganisms. The low ash content in fortified meals does satisfy the recommended minimum composition in accordance to Agunbiade and Ojezele (2010) report.

Crude fibre is a measure of the quantity of indigestible cellulose, pentosans, and lignins present in food products. Crude fibre has little food value but it gives bulk to the food and equally aids in regulating physiological functions. The statistical results as presented in Figure 7 show crude fibre composition of sorghum-soya blends and extrudates. The significantly $(p \leq 0.05)$ lower fibre content of extrudates $A$ to $D$ in extruded unfermented (EUF) samples as compared to that of raw flour blends (RF) could be as a result of mechanical shear effects of the extruding screw employed during the extrusion procedure. 
Fermentation caused a significant $(p \leq 0.05)$ reduction in the fibre content of the extrudates. This could probably be associated with the activities of the fermenting microoganisms which would have synthesized cellulose enzyme thereby breaking down the cellulose in the fermented extrudates. Crude fat (including oil) is one of the major components of the food that provides energy and essential lipids nutrients in many food products. Lipid constituent is a major determinant of overall physical characteristics, such as aroma, texture, the mouth-feel and appearance. Statistical analysis showed in Figure 6 indicates signi-ficant difference $(p \leq 0.05)$ among extrudates $A$ to $F$ in raw flour blends. Fat increased with soya bean level supple-mentation but as extrusion took over, extrudates $A, C$ and $E$ had no significant difference $(p \geq 0.05)$ but the increase in fat in extrudates $A, B, C$ and $D$ could be as a result of melting of the oils due to heat treatment applied while the drastic reduction in extrudates $E$ and $F$ could be attri-buted to physical loss in oil droplets which is similar to the findings of Nwabueze (2006). Declination in fat content after extrusion may also be as a result of starch/lipid com-plexes formation which resists the extraction of the oil. This is equally familiar with Camire (2001) reports. How-ever decrease in fat in extruded fermented (EF) could be attributed to the hydrolysis of glyceride to free fatty acids and glycerol.

Proteins are polymers of amino acids and their amount in a sample represents their quality index. Statistical results showed a significant difference $(p \leq 0.05)$, an indication that supplementation level affected the protein content of the raw flour blends (RF) and extruded unfermented (EUF). However, interaction between the extruded fermented (EF) exhibited a discrete behaviour with extrudate $A$ and $B$ having the highest values. The decrease in protein value in some of the extruded unfermented (EUF) could be as a result of interaction of amino acids in maillard reactions. This fact had been reported by Onyango et al. (2005). The reduction in protein in extruded unfermented (EUF) could as well be attributed to excessive heating during extrusion cooking. This finding supports the earlier report by Onyango et al. (2004) that heat denatures the protein of cytoplasm and that of the cell membrane. The increase in proportion of extruded fermented (EF) probably may be as a result of the activities of microorganisms involved in the fermentation of the mass which might have secreted extracellular enzymes that conesquently increased the protein contents. This is supported by the findings of Ojokoh et al. (2003). More also, the microorganisms made use of carbohydrate as energy source thereby producing carbon dioxide as a by-product leading to nitrogen concentration thereby increasing the protein in the fermenting mass as carbon ratio decrease resulting in the redistribution of the nutrient percentages. This is supported by the reports of Onyango et al. (2004).

Carbohydrate varied among the raw flour blends (RF), extruded fermented (EUF) and extruded fermented (EF).
The significant difference $(p \leq 0.05)$ in carbohydrate decrease with decrease in proportion of sorghum flour incorporation. The slight decrease in the extruded unfermented (EUF) could be attributed to the heating techniques applied in the cooking extrusion process. Apart from extrudate $B$, all extruded fermented (EF) samples showed decrease in carbohydrate (Figure 9). The lower carbohydrate content may be due to the activities of microorganisms on the starch components. This could be linked with enzymatic action on the starch component leading to break down of starch into various sugars. Since Bacillus species which dominated at $48 \mathrm{~h}$ of fermentation are amylolytic in action, this is substantiated by Fadahunsi and Duyilemi (2010) that Bacillus species are amylolytic. It had been reported by Achi (2005) that Bacillus species have certain enzymes such as amylase, galactanase, galactosidase, glycosidase and fructofuranosidase which are involved in the degradation of carbohydrate. Microbial amylases hydrolyze carbohydrate into sugars which are then readily digestible by humans. However the variations in the proximate composition could be associated with the processing techniques employed.

The tested organoleptic assayed for extruded unfermented such as aroma, texture, colour and acceptability indicated that all the samples were all acceptable. The preferred aroma may be likened to the fat component of the sample. Further studies should be carried out for comparison of sensory properties between extruded unfermented (EUF) and extruded fermented (EF) including tasting.

\section{Conclusion}

Fermentation of the sorghum-soya blend after extrusion improved the protein content compared to the raw samples. Evidence from the results of this research work showed that the sorghum-soya extrudates presents an exciting opportunity in processing of cereal-legume into a convenience ready-to eat inexpensive food products which can store well without refrigeration that require only reconstitution in warm water.

\section{Conflict of Interest}

The author(s) have not declared any conflict of interest.

\section{REFERENCES}

Achi OK (2005). Traditional fermented protein condiments in Nigeria. Afr. J. Biotechnol. 4(13):612-1621.

Agunbiade SO, Ojezele O (2010). Quality evaluation of instant breakfast meals fabricated from Maize, Sorghum, Soybean and Yam bean(Sphenostylis stenocarpa) World J. Dairy Food Sci. 5(1): 67-72.

AOAC (1990). Official Methods of Analysis $15^{\text {th }}$ (ed), Association of Official Analytical Chemist, Washington DC. pp.125-576. 
Camire ME (2001). Extrusion cooking.In technologies and applications, ed. Guy R, England:Wood head Publishing Co. pp. 109-129.

Cowan ST, Steel KJ (1990).Manual for the identification of medical bacteria. $4^{\text {th }}($ ed), Uuniversity press, Cambridge. p. 58.

Edema MO, Sanni LO, Sanni Al (2005). Evaluation of maize soybean flour blends for sour maize bread production in Nigeria. Afr. J. Biotechnol. 4(9):911-918.

Efiuvwevwere B, Akoma O (1997). Microbiological studies on a Nigerian maize product, kwoka, supplemented with soybean. J. Food Saf. 17:249-259.

Enujiugha VN (2009). Major fermentative organisms in some Nigerian soup condiments. Pak. J. Nutr. 8:279-283.

Ezeama FC, Ihezie IC (2006). Microbiological and sensory evaluations of fermented Rice snacks (masa) supplemented with soybean. J. Food Technol. 4(4):345-349.

Fadahunsi IF, Duyilemi PO (2010). Microbiological and enzymatic studies during the development of an 'Iru' (a local Nigerian indigenous fermented condiment) like condiment from Bambara Nut[Voandzeia subterranean (L) Thours]. Malay. J. Microbiol. 6(2): 123-126.

Guy R (2001). Extrusion cooking: Technologies and applications. Cambridge: p. 288. Woodhead Publishing Co.

Ihekoronye Al, Ngoddy PO (1985). Integrated Food Science and Technology for the Tropics. Macmillan Publishers, London. pp. 5-239.

Iwe MO (1998). Effect of extrusion cooking on functional properties of mixtures of full-fat soy and sweet potato. Plant Foods Hum. Nutr. 53: $37-46$.
Kirk RR, Sawyer R (1991). Pearson's composition and analysis of foods. $9^{\text {th }}($ ed), Longman, Singapore. p. 45.

Mills CG, Hine RH, Hancock JD, Gugle TL (1993). Extrusion of Sorghum grain and soybeans for Lactating cows. KSU Swine Day. pp. 9-12.

Nwabueze TU (2006). Water absorption and solubility indices of extruded African bread fruit (Treculia Africana). J. Food Technol. 4 (1):64-69.

Ojokoh AO, Adetuyi FC, Akinyosoye FA, Oyetayo VO (2003). Fermentation studies of Roselle(Hibiscus sabdariffa) calyces neutralised with trona. Biotechnology; A tool for global development $17^{\text {th }}$ Annual Conference of Biotechnology Society of Nigeria. Abkol, Akure. pp. 90-93.

Omafuvbe BO, Esosuakpo EO, Oladejo TS, Toye AA (2007). Effect of soaking and roasting dehulling methods of soybean on Bacillus fermentation of soy-daddawa. Am. J. Food Technol. 2(4):257-264

Onyango C, Noetzold H, Bley T, Henle T (2004). Proximate composition and Digestibility of fermented and extruded uji from maize-finger millet blend. Lebensmittel Wissenchaft Technol. 37:827-832.

Onyango C, Noetzold H, Ziems A, Hofmann T, Bley T, Henle T (2005). Digestibility and antinutrient properties of acidified and extruded maize-finger millet blend in the production of uji. Lebensmitted Wissenschaft Technol. 38:697-707

Osundahunsi O F (2006). Functional properties of extruded soybean with plantain flour blends. J. Food Agric. Environ. 4(1):57-60. 